\title{
Diagnostic and prognostic value of serum soluble CD163 in cirrhotic patients with hepatitis $C$ virus-related hepatocellular carcinoma before and after locoregional therapy
}


Ahmed Samir Allam ${ }^{1}$ and Eslam Safwat ${ }^{1 *}$

\begin{abstract}
Background: Tumor-associated macrophages (TAMs), inflammatory cells in tumor microenvironment, are crucial for the tumor occurrence and progression which in turn increase the expression of soluble CD163 (sCD163). Nevertheless, not much has been established regarding SCD163 and its connection to HCC diagnosis and prognosis. This study was conducted to evaluate the diagnostic and prognostic role of sCD163 in patients with HCC on top of HCV-related liver cirrhosis. Forty adult patients with HCV-related liver cirrhosis and HCC (HCC group) were randomly selected and subjected to locoregional therapies, either transarterial chemoembolization (TACE) or radiofrequency ablation (RFA). Four patients were excluded because of portal vein invasion. Another group of 20 patients with liver cirrhosis only served as controls (LC group). Routine laboratory studies and abdominal ultrasound were done for all. Alphafetoprotein (AFP) and sCD163 were measured twice, at baseline and 1-month post-intervention, using a commercially available enzyme-linked immunosorbent assay kit.
\end{abstract}

Results: At baseline, $\mathrm{sCD} 163$ showed an insignificant higher value in HCC group $(p>0.05)$. The best cutoff value for sCD163 and AFP was $6.2 \mathrm{mg} / \mathrm{L}$ and $195 \mathrm{ng} / \mathrm{mL}$, respectively. AFP had a larger area under the curve (0.88 vs. 0.767). An overall significant decline was seen in SCD163 after treatment ( $6.5 \pm 1.5$ to $3.1 \pm 2.5 \mathrm{mg} / \mathrm{L}$; $p<0.001$ ), while AFP showed an insignificant decrease $(p>0.05)$. Also, SCD163 decreased significantly in the eradicated cases $(6.1 \pm 1.4 \mathrm{mg} / \mathrm{L}$ before intervention vs. $2.3 \pm 1.4 \mathrm{mg} / \mathrm{L}$ after intervention, $p<0.01$ ), while there was a significant increase in the recurrent cases ( $8.4 \pm 0.4 \mathrm{mg} / \mathrm{L}$ before intervention vs. $10.3 \pm 1.6$ after intervention; $p<0.05)$. Moreover, SCD163 showed a significant difference in its pre-intervention and post-intervention values between recurrent and eradicated HCC cases $(p<0.01)$.

Conclusions: It is concluded that SCD163 has a minor role as a diagnostic marker for HCC, yet it could be used as a good prognostic marker in predicting the tumor response to locoregional therapies.

Keywords: HCC, Soluble CD163, Transarterial chemoembolization, Radiofrequency ablation

\footnotetext{
* Correspondence: eslam_safwat@med.asu.edu.eg

'Department of Internal Medicine, Faculty of Medicine, Ain Shams University,

Cairo, Egypt

Full list of author information is available at the end of the article
}

\section{Springer Open}

(c) The Author(s). 2021 Open Access This article is licensed under a Creative Commons Attribution 4.0 International License, which permits use, sharing, adaptation, distribution and reproduction in any medium or format, as long as you give appropriate credit to the original author(s) and the source, provide a link to the Creative Commons licence, and indicate if changes were made. The images or other third party material in this article are included in the article's Creative Commons licence, unless indicated otherwise in a credit line to the material. If material is not included in the article's Creative Commons licence and your intended use is not permitted by statutory regulation or exceeds the permitted use, you will need to obtain permission directly from the copyright holder. To view a copy of this licence, visit http://creativecommons.org/licenses/by/4.0/. 


\section{Background}

Hepatocellular carcinoma (HCC) poses a major global health problem as it is the fifth most common cancer and the second most frequent cause of cancer-related death worldwide, with an estimate of $7 \%$ of all cancers and with 5-year survival of $18 \%$ [1]. Most of HCC cases arise within chronically inflamed liver tissues, with the majority due to viral hepatitis with HBV ( $54 \%$ of all HCCs) or HCV (31\% of all HCCs), cirrhosis (80\% of all HCCs), high alcohol consumption, obesity, genetic disorders such as hemochromatosis, and exposure to aflatoxin-contaminated foodstuff [2].

In addition to the underlying liver cirrhosis as a pathogenic precursor of $\mathrm{HCC}, \mathrm{HCV}$ may unintentionally be a precursor to HCC development through several mechanisms including persistent hepatocyte inflammation and immune-mediated intracellular oxidative stress damage and deregulation of cell signaling pathways induced by viral proteins ( $\mathrm{HCV}$ core, NS3, and NS5A/B). Moreover, $\mathrm{HCV}$ facilitates metabolic re-programming to steatosis, which in turn leads to progressive fibrosis and HCC [3].

As a well-known fact, surgical resection and liver transplantation (LT) are the mainstay curative tools for the long-term survival, yet despite the advances in this field, only $5-15 \%$ of HCC lesions are estimated to be readily resectable. This might be attributed to many factors including tumor location and size or severity of the underlying liver disease [4].

Thus, locoregional therapy is considered among the most important and feasible lines of HCC treatment including radiofrequency ablation (RFA) and transarterial chemoembolization (TACE). RFA is the best tool in patients with early stage of $\mathrm{HCC}$ who are not eligible for surgical resection or LT [5]. On the other hand, TACE has been shown to be a good therapeutic option in patients with Child-Pugh A-B cirrhosis with no local vascular invasion or extrahepatic cancer-related symptoms, and it could be applied before LT as a neoadjuvant therapy or as a means of downstaging of patient's condition [6].

Hepatocellular carcinoma usually progresses with subclinical events or with minor abnormalities in hepatic functions escaping early diagnosis, which in turn makes screening and surveillance of this fatal disease highly crucial, giving a good chance for early intervention. In standard clinical practice, imaging studies are so long considered the gold standard non-invasive methods, where abdominal ultrasonography is the most widely used screening imaging study, followed by triphasic computed tomography (CT) or dynamic magnetic resonance imaging (MRI) as confirmatory tools [7]. However, the diagnostic performance of imaging technologies is sometimes unsatisfactory, particularly for the diagnosis of small lesions and early-stage HCC [8].

Serological biomarkers can provide a diagnostic support for the imaging results and may provide a crucial breakthrough in detecting biochemical changes prior to the image-based identification of hepatic malignant nodules. Alpha-fetoprotein (AFP) is the most extensively tested biomarker in HCC. However, it has a limited diagnostic performance in HCC surveillance with a sensitivity of only $25 \%$ for nodules smaller than $3 \mathrm{~cm}$ [9]. Besides, variable levels of AFP might be seen in liver cirrhosis or might reflect flares of underlying viral infection [10]. This raises our need for identification of new more reliable biomarkers for early diagnosis of HCC.

Mounting evidence has shown that macrophages are involved as a key pathogen in many conditions that range from severe sepsis to carcinogenesis [11]. According to their functional status, macrophages are further subclassified into M1 (classically activated) and M2 (alternatively activated), where tumor-associated macrophages (TAM) have an M2 phenotype with pro-tumoral impacts [12]. $\mathrm{HCC}$ is a typical example of an inflammation-related tumor, as more than $90 \%$ of HCC cases arise in the context of hepatic injury and inflammation, a fact that was shown in some anecdotal studies where an interaction between HCC cells and hepatic macrophages was illustrated by the association between the density of the TAMs and HCC progression. Consequently, macrophages may represent a possible therapeutic target in HCC [13].

Moreover, macrophage-associated markers have raised scientists' interest as possible markers of HCC presence and progression. Among these markers is the hemoglobinhaptoglobin scavenger receptor CD163, which is located exclusively on the cell surface of macrophages and monocytes. Upon macrophage activation, CD163 is shed from the cell surface into the circulation. Thus, the soluble form of CD163 (sCD163) might be considered a promising specific marker of macrophage activation that might have a good capacity as a biomarker of the severity and outcome of various liver diseases, including HCC [14].

In this study, we aimed to evaluate the diagnostic utility of serum sCD163 in HCC and to study its role as a prognostic marker before and after locoregional intervention.

\section{Methods}

This study was a prospective single-center study conducted on 40 randomly selected adult patients with $\mathrm{HCV}$ related liver cirrhosis and HCC (HCC group). The diagnosis of $\mathrm{HCC}$ was confirmed according to the American Association for the Study of Liver Diseases (AASLD) guidelines in 2011 [15]. Another group of 20 age- and sexmatched subjects with only liver cirrhosis without HCC participated as a control group (LC group). The study was carried out on patients attending the hepatology outpatient clinics or admitted at the internal medicine department, in collaboration with the Radiology Department, Ain Shams University Hospitals, during the interval between September 2018 and May 2019. 
During patients' selection, those with any contraindication for locoregional therapies were excluded from the study, including any radiological evidence of major portal or hepatic vein branch invasion, extrahepatic metastases or other non-hepatic malignancies, Child-Pugh class $\mathrm{C}$ cirrhosis or impaired coagulation profile (platelet count below $50 \times 10^{9} / \mathrm{L}$ or prothrombin activity below $50 \%$ ), active gastrointestinal bleeding, and pregnancy.

The study was performed according to the ethical standards for human experimentation and in accordance with the ethical principles of the 1975 Declaration of Helsinki that was granted by the local Ethics Committee of Ain Shams University. Before enrollment in the study and after explaining the aim of the study and the nature of the investigations and interventions required, an informed written consent was obtained from all participants.

Patients in both groups were subjected to a thorough medical history, clinical assessment, and laboratory investigations including complete blood count, hepatic and renal profiles, and viral markers $(\mathrm{HCV} \mathrm{Ab}$ and HBsAg). Serum AFP was measured in all subjects using human AFP EIA kit (CanAg Diagnostics; Gothenburg, Sweden) according to the manufacturer's instructions.

Serum sCD163 levels were determined with the Macro163 sandwich ELISA (Trillium Diagnostics, Bangor, Maine, USA) according to the recommendation of the manufacturer. The assay is based on the principle of the sandwich ELISA. A polyclonal antibody recognizing CD163 is immobilized on the surface of a microtiter plate. After incubation with the sample or recombinant CD163 standard, a second biotinylated monoclonal antibody recognizing CD163 is added. Detection of the latter was done by adding streptavidin-horseradish peroxidase (HRP). Using TMB as substrate for the enzyme HRP, the amount of sCD163 protein could be quantified. Before use, all buffers should be allowed to reach room temperature $\left(20-25{ }^{\circ} \mathrm{C}\right)$ except for reagent $\mathrm{F}$ (TMB) which is kept at $4{ }^{\circ} \mathrm{C}$. The washing buffer (reagent $\mathrm{D}$ ) is diluted 10 times with demineralized water before use. The dilution buffer (reagent E) is diluted 10 times with demineralized water before use.

Abdominal ultrasound was done for all patients, and only those in HCC group underwent further confirmatory imaging studies including abdominal triphasic CT or dynamic MRI as a part of HCC diagnosis. Child-Pugh classification was calculated for all studied patients to assess the severity of liver disease, depending on patients' clinical and laboratory data (ascites, hepatic encephalopathy, serum albumin, serum bilirubin, and international normalized ratio INR).

Radiofrequency ablation was applied for patients with very early (BCLC-0) or early (BCLC-A) HCC who are not candidates for liver resection or $\mathrm{LT}$, with tumor size less than $5 \mathrm{~cm}$ in diameter or less than three nodules with a maximum diameter of $3 \mathrm{~cm}$. RFA was performed using a specific electrode into the targeted lesion that generates a zone of thermal destruction encompassing the tumor (temperature range $60-100{ }^{\circ} \mathrm{C}$ ). A heat-sink effect is also generated by the convective cooling by adjacent blood vessels when ablated tissues are heated [16]. TACE was applied in patients with intermediate BCLC stages who had Child-Pugh A-B cirrhosis, large or multifocal HCC, which were not suitable for surgical resection or RFA. It was performed in a super-selective way, depending on the details provided in the imaging studies, by injecting the feeding artery of tumor nodule with the emulsion of lipiodol chemotherapy drug and then use the same vascular embolization to obtain the synergistic effect of cytotoxic activity of drug and ischemia [17]. Both techniques were performed by an expert interventional radiologist.

During follow-up, AFP, sCD163, and imaging studies were performed twice in the HCC cohort (baseline and 1-month post-intervention).

\section{Statistical methods}

The collected data were coded, tabulated, and statistically analyzed using the IBM SPSS statistics (Statistical Package for Social Sciences) software version 18.0, IBM Corp., Chicago, USA. Descriptive statistics were done for quantitative data as mean \pm SD (standard deviation) for normally distributed data, and median and 1st and 3rd interquartile range for non-normally distributed data, while it was done for qualitative data as number and percentage.

For quantitative variables, independent $t$-test was used in cases of two independent groups with normally distributed data, paired $t$-test in cases of two dependent groups with normally distributed data, Mann-Whitney $U$ in cases of two independent groups with non-normally distributed data, and Wilcoxon signed rank test in cases of two dependent groups with non-parametric data.

In qualitative data, analyses for independent variables were done using Chi square test for differences between proportions and Fisher's exact test for variables with small, expected numbers.

ROC curve was constructed to evaluate the performance of different tests and differentiate between certain groups. The level of significance was taken as $p$-value < 0.05 is significant and $<0.01$ is highly significant, otherwise is insignificant.

\section{Results}

A total of 60 subjects were recruited in this study, including 40 patients with proved liver cirrhosis and HCC with mean age of $57.1 \pm 6.8$ years old ( 28 were males (70\%) and 12 females (30\%)), and 20 patients with liver cirrhosis only with mean age of $54.8 \pm 7.6$ years old (12 
were males (60\%) and 8 females (40\%)). Hepatitis C virus $(\mathrm{HCV})$ was the underlying etiology in all included subjects. Child-Pugh A class was found in 32 patients (23 in the HCC group and 9 in the LC group), Child-Pugh B in 27 patients (17 in the HCC group and 10 in the $\mathrm{LC}$ group), and Child-Pugh $\mathrm{C}$ in 1 patient in the liver cirrhosis group. Demographic and laboratory data of all studied subjects are shown in Table 1.

At baseline, the mean value of sCD163 was higher in the HCC group as compared to the LC group, yet nonsignificant $(6.6 \pm 1.6 \mathrm{mg} / \mathrm{L}$ vs. $6.1 \pm 1 \mathrm{mg} / \mathrm{L} ; p=0.079)$. On the other hand, AFP showed a significant difference between the 2 groups with a median value much higher in the $\mathrm{HCC}$ group (305 $\mathrm{ng} / \mathrm{ml}$ vs. $25 \mathrm{ng} / \mathrm{ml} ; p<0.001$ ) (Table 2). Among the randomly selected 40 HCC patients, 4 of them were found to have portal vein invasion and were excluded from underlying locoregional therapy. None had PVT in LC group. SCD163 was significantly higher among cases with portal vein thrombosis $(8.4 \pm 0.2 \mathrm{mg} / \mathrm{L}$ vs. $6.0 \pm 1.5 \mathrm{mg} / \mathrm{L} ; p<0.001)$, while AFP showed no significant difference regarding PVT.

For the estimation of diagnostic efficacy, ROC curve was performed for both sCD163 and AFP to get the best cutoff value to discriminate between $\mathrm{HCC}$ and LC group. Area under the curve (AUC) for serum sCD163 was 0.767 (95\% CI 0.644-0.889) while that of AFP was 0.880 (95\% CI $0.79-0.969)$. Both were statistically significant $(p<0.01)$.
According to the curve, the best cutoff value for sCD163 was $6.2 \mathrm{mg} / \mathrm{L}$, above which the sensitivity to discriminate HCC patients was $63.9 \%$, and below which the specificity to discriminate LC patients was $85 \%$ with $71.4 \%$ diagnostic accuracy (true results for both), while AFP could differentiate HCC from LC cases at a cutoff value of $195 \mathrm{ng} / \mathrm{mL}$, with $75 \%$ sensitivity, $85 \%$ specificity, and $78.6 \%$ diagnostic accuracy (Table 3, Fig. 1).

The approved selection criteria were applied for locoregional therapies, where 26 patients were eligible for TACE and 10 patients for RFA. During follow-up (1 month) after intervention, 6 patients had HCC recurrence ( 3 in RFA and 3 in TACE). At that time, 1 month after therapeutic intervention, sCD163 showed an overall significant decline from a mean value of $6.5 \pm 1.5$ to $3.1 \pm$ $2.5 \mathrm{mg} / \mathrm{L}$ in all treated case; $p<0.001$. Also, AFP decreased from a median value of 327 to $280 \mathrm{ng} / \mathrm{ml}$, yet it was an insignificant decline $(p=0.66)$ (Table 4$)$.

For further details, sCD163 and AFP were compared in both recurrent and eradicated HCC cases before and after intervention. sCD163 showed a significant decrease in the eradicated cases $(n=30)$, with a mean value of $6.1 \pm$ $1.4 \mathrm{mg} / \mathrm{L}$ before intervention as compared to $2.3 \pm 1.4$ $\mathrm{mg} / \mathrm{L}$ after intervention $(p<0.001)$, while it showed a significant increase in the recurrent cases $(n=6)(8.4 \pm 0.4$ $\mathrm{mg} / \mathrm{L}$ before intervention vs. $10.3 \pm 1.6$ after intervention; $p=0.022$ ). Moreover, $\mathrm{sCD} 163$ showed a significant

Table 1 Demographic and laboratory data of studied groups

\begin{tabular}{|c|c|c|c|c|}
\hline \multicolumn{2}{|l|}{ Parameter } & \multirow{2}{*}{$\begin{array}{l}\text { HCC group }(n=40) \\
57.1 \pm 6.8\end{array}$} & \multirow{2}{*}{$\begin{array}{l}\text { LC group }(\boldsymbol{n}=\mathbf{2 0}) \\
54.8 \pm 7.6\end{array}$} & \multirow{2}{*}{$\begin{array}{l}p \\
0.236\end{array}$} \\
\hline Age (years) & & & & \\
\hline $\mathrm{BMI}\left(\mathrm{Kg} / \mathrm{m}^{2}\right)$ & & $24.7 \pm 2.1$ & $25.4 \pm 3$ & 0.365 \\
\hline \multirow[t]{2}{*}{ Gender } & Male $n(\%)$ & $28(70 \%)$ & $12(60 \%)$ & \multirow[t]{2}{*}{0.439} \\
\hline & Female $n(\%)$ & $12(30 \%)$ & $8(40 \%)$ & \\
\hline \multirow[t]{3}{*}{ Child-Pugh class } & $A \cap(\%)$ & $23(57.5 \%)$ & $9(45 \%)$ & \multirow[t]{3}{*}{0.305} \\
\hline & $\mathrm{B} \cap(\%)$ & $17(42.5 \%)$ & $10(50 \%)$ & \\
\hline & $C n(\%)$ & $0(0.0 \%)$ & $1(5 \%)$ & \\
\hline $\mathrm{ALT}(\mathrm{U} / \mathrm{L})$ & & $57.0 \pm 28.3$ & $40.2 \pm 17.3$ & 0.006 \\
\hline AST (U/L) & & $57.9 \pm 31.0$ & $30.9 \pm 17.1$ & $<0.001$ \\
\hline $\operatorname{ALP}(U / L)$ & & $79.2 \pm 23.6$ & $88.4 \pm 30.7$ & 0.25 \\
\hline S. albumin (g/dl) & & $3.6 \pm 0.4$ & $3.4 \pm 0.6$ & 0.156 \\
\hline T. bilirubin (mg/dl) & & $1.5 \pm 0.4$ & $1.7 \pm 0.6$ & 0.13 \\
\hline D. bilirubin (mg/dl) & & $0.7 \pm 0.2$ & $0.9 \pm 0.4$ & 0.117 \\
\hline INR & & $1.4 \pm 0.38$ & $1.31 \pm 0.37$ & 0.37 \\
\hline Hemoglobin (g/dL) & & $11.0 \pm 1.5$ & $10.3 \pm 0.9$ & 0.022 \\
\hline $\operatorname{WBCs}\left(\times 10^{3} / \mathrm{mL}\right)$ & & $7 \pm 2.3$ & $5.6 \pm 1.4$ & 0.28 \\
\hline Platelets $\left(\times 10^{3} / \mathrm{mL}\right)$ & & $148.0 \pm 36.5$ & $137.4 \pm 41$ & 0.313 \\
\hline S. creatinine (mg/dL) & & $0.85 \pm 0.32$ & $0.79 \pm 0.32$ & 0.516 \\
\hline S. sodium (mEq/L) & & $137.6 \pm 3.8$ & $136.3 \pm 3.1$ & 0.187 \\
\hline S. potassium (mEq/L) & & $4.0 \pm 0.5$ & $4.2 \pm 0.4$ & 0.129 \\
\hline
\end{tabular}


Table 2 Comparison between the 2 studied groups as regards baseline sCD163 and AFP

\begin{tabular}{|c|c|c|c|c|c|c|}
\hline \multirow[t]{2}{*}{ Parameter } & \multicolumn{2}{|c|}{ sCD163 (mg/L) } & \multirow[t]{2}{*}{$p$} & \multicolumn{2}{|c|}{ AFP (ng/ml) } & \multirow[t]{2}{*}{$p$} \\
\hline & Mean \pm SD & Range & & Median & IQR & \\
\hline HCC group $(n=40)$ & $6.6 \pm 1.6$ & $3.7-8.8$ & 0.079 & 305 & $145.8-550.5$ & $<0.001$ \\
\hline LC group $(n=20)$ & $6.1 \pm 1$ & $4.9-8.3$ & & 25 & $12.8-110.5$ & \\
\hline
\end{tabular}

$I Q R$ interquartile range

difference in its pre-intervention mean values between recurrent and eradicated HCC cases $(p<0.001)$, and it had a significant difference between both subgroups post-intervention $(p<0.001)$. On the other hand, AFP showed insignificant changes in both recurrent and eradicated cases $(p>0.05)$ (Table 5).

The diagnostic accuracy of both biomarkers was assessed for the discrimination between patients with recurrent and eradicated HCC. ROC curve was performed showing an AUC of AFP before and after intervention 0.528 (95\% CI $0.311-0.744)$ and 0.642 (95\% CI $0.374-$ $0.910)$, respectively $(p>0.05)$, while that of $\mathrm{sCD} 163$ was 0.986 (95\% CI $0.000-1.000$ ) and 0.994 (95\% CI $0.000-$ $1.000)$, respectively $(p<0.001)$. A highly significant difference was found between AUROC of AFP and sCD163 $(p<0.001)$. As the AUC of AFP was extremely low, a cutoff value could not be postulated. The best cutoff value of $\mathrm{sCD} 163$ at $7.8 \mathrm{mg} / \mathrm{L}$ before intervention had a sensitivity of $100 \%$ and specificity of $90 \%$, with a positive predictive value of $66.7 \%$, and a negative predictive value of $100 \%$, with a diagnostic accuracy of $91.7 \%$, and at best cutoff value of $5 \mathrm{mg} / \mathrm{L}$ after intervention, a sensitivity of $100 \%$ and specificity of $86.7 \%$ were detected. The positive predictive value of the test was $60 \%$, while the negative predictive value of the test was $100 \%$. The diagnostic accuracy of the test was $88.9 \%$ (Fig. 2).

The most relevant demographic, clinical, and biochemical data found in recurrent and eradicated HCC cases were age of patients, Child-Pugh score, s. albumin, and number and size of HCC focal lesions $(62.8 \pm 3.1$ vs. $56.0 \pm 6.9$ years, $p<0.001 ; 7.2 \pm 0.8$ vs. $5.9 \pm 1.0, p=0.008$; $3.3 \pm 0.2$ vs. $3.7 \pm 0.4 \mathrm{~g} / \mathrm{dl}, p=0.036 ; 3.0 \pm 0.0$ vs. $1.7 \pm 0.7, p$ $<0.001 ; 6.2 \pm 1.6$ vs. $3.3 \pm 1.2 \mathrm{~cm}, p<0.001$, in recurrent and eradicated HCC cases, respectively) (Table 6).

\section{Discussion}

Globally, HCC is reported to be the second most common cause of cancer-related death. Chronic HCV remains on the top of the etiologic factors, considered as a strong promoter of inflammation and hence hepatocarcinogenesis [18]. In recent years, despite the revolution in HCV treatment by the direct-acting antiviral agents (DAAs) with achievement of high rates of sustained virologic response (SVR), the risk of HCV-related HCC could not be fully eradicated, particularly in those with advanced liver disease [19]. Consequently, diagnosis of $\mathrm{HCC}$ at early stages seems crucial giving an optimum chance for successful curative treatment, but frequently a challenge due to the scarcity of symptoms until discovered at late stage. Besides, current screening strategies comprising ultrasound for high-risk patients (mainly those with cirrhosis) consume substantial amounts of resources, and sensitivity is often suboptimal [20].

For years, serum AFP has been used as the most useful serum marker for diagnosis of HCC. However, serum AFP is not always elevated to a diagnostic level in all patients, particularly in small $\mathrm{HCC}$, and considerable numbers of patients with more advanced stages would be missed unless another diagnostic tool is used [21]. Thus, it seems implausibly demanding to require a biomarker that helps in diagnosis and follow-up of HCC after locoregional treatment.

Recent studies have raised the significance of the tumor microenvironment in the development, metastasis, and recurrence of HCC. Tumor-associated macrophages (TAMs) are copious in the tumor microenvironment and vital in tumor development and metastasis [22]. Upon activation of the resident liver macrophages (Kupffer cells) by various stimuli including hepatocyte death, it releases a variety of interleukins, cytokines, and reactive oxygen species which modulate hepatocellular growth. Soluble CD163 was shown to reflect macrophage activity in serum and can be regarded as a marker for activated macrophages. Thus, soluble CD163 has shown a promising capacity as a biomarker of the severity and outcome of various liver diseases, including HCC [23].

Table 3 Diagnostic performance of the best cutoff values of sCD163 and AFP in discriminating HCC groups from LC group

\begin{tabular}{|c|c|c|c|c|c|c|c|c|}
\hline Parameter & Cutoff value & $\begin{array}{l}\text { AUC } \\
(95 \% \mathrm{Cl})\end{array}$ & $\begin{array}{l}\text { Sensitivity } \\
\text { (\%) }\end{array}$ & $\begin{array}{l}\text { Specificity } \\
\text { (\%) }\end{array}$ & $\begin{array}{l}\text { PPV } \\
\text { (\%) }\end{array}$ & $\begin{array}{l}\text { NPV } \\
(\%)\end{array}$ & $\begin{array}{l}\text { Accuracy } \\
\text { (\%) }\end{array}$ & $p$ \\
\hline $\begin{array}{l}\text { SCD163 } \\
\text { (mg/L) }\end{array}$ & 6.2 & $\begin{array}{l}0.767 \\
(0.644-0.889)\end{array}$ & 63.9 & 85 & 88.5 & 56.7 & 71.4 & $<0.01$ \\
\hline $\begin{array}{l}\text { AFP } \\
(\mathrm{ng} / \mathrm{ml})\end{array}$ & 195 & $\begin{array}{l}0.88 \\
(0.790-0.969)\end{array}$ & 75 & 85 & 90 & 65.4 & 78.6 & $<0.01$ \\
\hline
\end{tabular}




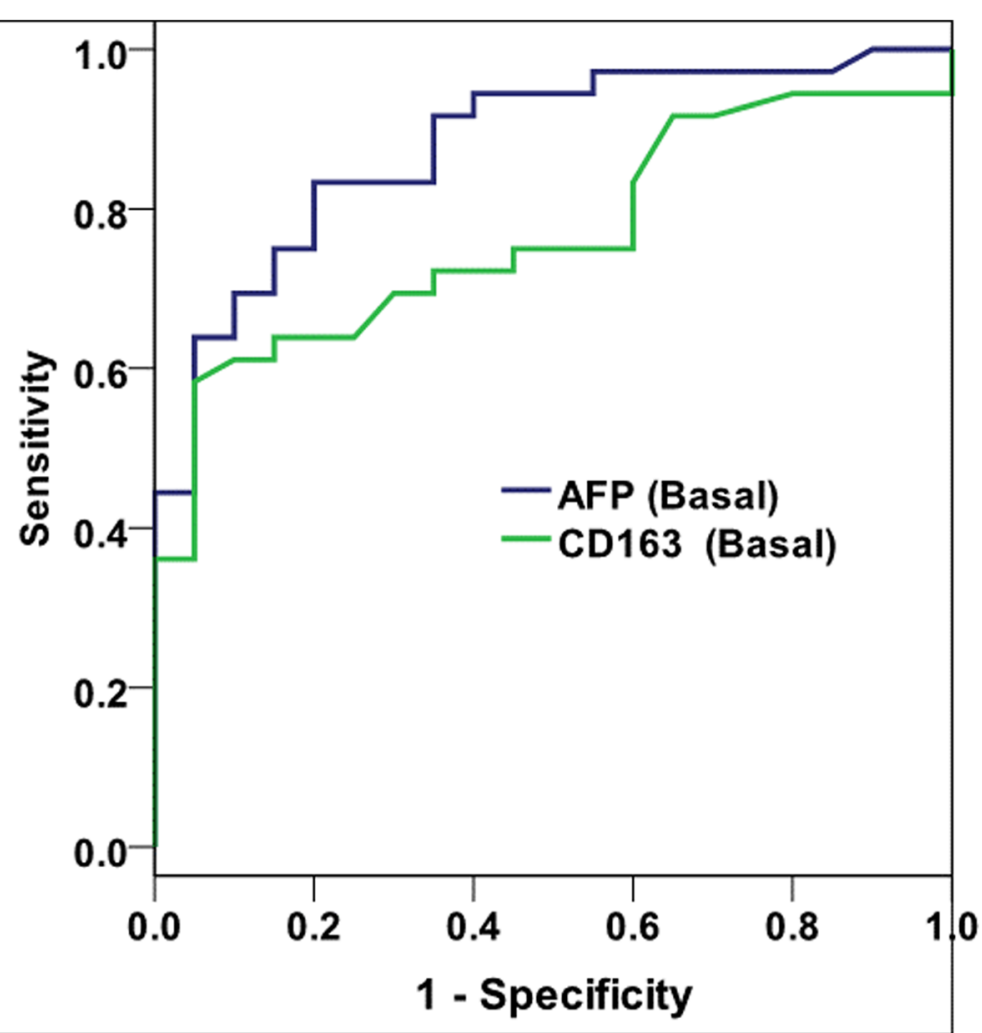

Fig. 1 ROC curve showing comparison of the diagnostic performance of serum sCD163 and AFP for discriminating HCC group from liver cirrhosis group

In this study, we aimed at evaluating the diagnostic value of serum level of sCD163 as a tumor marker for HCC and studying its prognostic performance before and after locoregional therapies.

Sixty subjects were included in the present study, classified into 2 groups: group I (HCC group) including 40 randomly selected patients with $\mathrm{HCV}$-related liver cirrhosis and HCC (excluding BCLC class D) who underwent either RFA or TACE, and group II (LC group) including 20 age- and sex-matched patients with HCVrelated liver cirrhosis only. Among the randomly selected HCC patients, 4 were excluded due to portal vein thrombosis; thus, 36 patients were subjected to locoregional treatment according to the selective criteria for intervention.

Among HCC patients, males were predominantly affected (28 males (70\%) vs. 12 females (30\%)); a result that is in accordance with a recent single-center Egyptian study that aimed at identifying the trend, possible risk factors, and any pattern change of HCC over a decade, [24] showing a significant increase in male proportion from 82.5 to $87.6 \%(p=0.009), \mathrm{M} / \mathrm{F}$ from $5: 1$ to $7: 1$ in periods I (1993-1997) and II (1998-2002), respectively. This finding might be explained in part by exposure to risk factors and sex hormones. It has been speculated that estrogens, androgens, degree of iron deposition, and difference in ethnicity could modulate hepatocarcinogenesis and explain the higher incidence of HCC in men [25].

For HCC diagnosis, the present study did not demonstrate any significant difference in serum sCD163 levels between patients with HCC and LC patients $(p=0.079)$, yet AFP showed a significant difference between the 2 groups with a median value much higher in HCC group

Table 4 Pre- and post-intervention values of AFP and sCD163 in all treated HCC cases $(n=36)$

\begin{tabular}{llll}
\hline Parameter & Pre-intervention value & Post-intervention value & \\
\hline AFP $(\mathbf{n g} / \mathbf{m l})$ median $(\mathrm{IQR})$ & $327(154.5-687)$ & $280(202.8-768)$ & $0.66^{\mathrm{a}}$ \\
$\mathbf{s C D} 163 \mathbf{~} \mathbf{m g} / \mathbf{L})$ mean \pm SD & $6.5 \pm 1.5(3.7-8.8)$ & $3.1 \pm 2.5(0.8-9.2)$ & $<0.001^{\mathrm{b}}$ \\
\hline
\end{tabular}


Table 5 AFP and SCD163 in recurrent and eradicated HCC cases pre- and post-locoregional intervention

\begin{tabular}{|c|c|c|c|}
\hline Variable & Recurrent HCC cases $(n=6)$ & Eradicated HCC cases $(n=30)$ & $p$ \\
\hline \multicolumn{4}{|l|}{ AFP (ng/ml) } \\
\hline Pre-intervention & & & $0.832^{\mathrm{a}}$ \\
\hline Median (IQR) & $356(232.5-502.5)$ & $305(138.5-742.5)$ & \\
\hline \multicolumn{4}{|l|}{ Post-intervention } \\
\hline Median (IQR) & 365 (235.8-1999.8) & $249(182-634)$ & $0.279^{\mathrm{a}}$ \\
\hline$p$ & $0.832^{\mathrm{b}}$ & $0.279^{b}$ & \\
\hline \multicolumn{4}{|l|}{ sCD163 (mg/L) } \\
\hline Pre-intervention & & & $<0.001^{c}$ \\
\hline Mean $\pm S D$ & $8.4 \pm 0.4$ & $6.1 \pm 1.4$ & \\
\hline \multicolumn{4}{|l|}{ Post-intervention } \\
\hline Mean $\pm S D$ & $10.3 \pm 1.6$ & $2.3 \pm 1.4$ & $<0.001^{c}$ \\
\hline$p$ & $0.022^{d}$ & $<0.001^{\mathrm{d}}$ & \\
\hline
\end{tabular}

${ }^{\mathrm{a}}$ Mann-Whitney $(U)$ test

${ }^{b}$ Wilcoxon rank sum test

Independent $t$ test

${ }^{\mathrm{d}}$ Paired $t$ test

$(p<0.001)$. These results might be explained by the fact that sCD163 expression is significantly increased in liver tissues of chronic HCV patients, correlated well with the degree of hepatic fibrosis and cirrhosis, which is in line with another recent publication confirming $\mathrm{SCD} 163$ as a fibrosis predictor [26]. Moreover, an anecdotal study reported elevated levels of plasma sCD163 in patients with acute and chronic viral hepatitis [27]. Taken together, all these findings could explain the poor diagnostic value of sCD163 in differentiating HCC from mere liver cirrhosis.

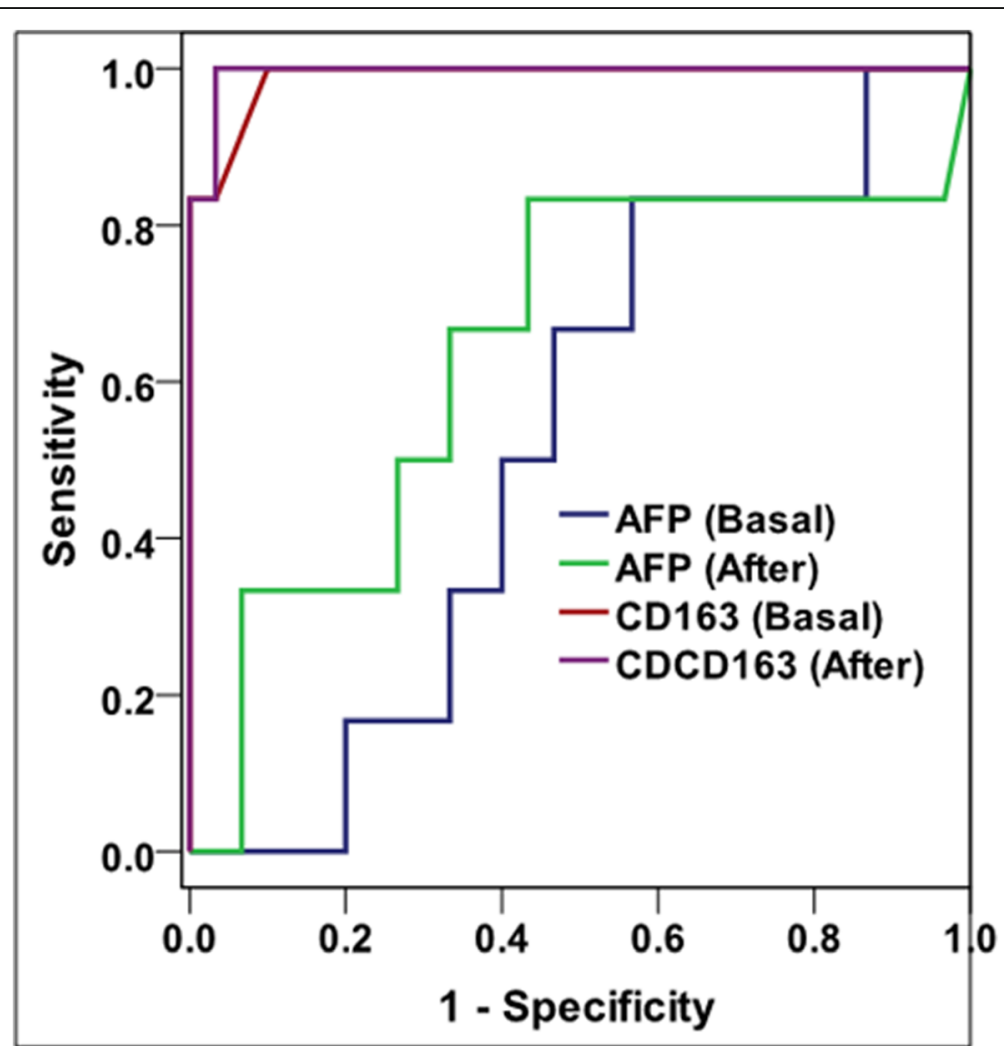

Fig. 2 ROC curve showing comparison of the diagnostic performance of pre- and post-intervention sCD163 and AFP in differentiating recurrent from eradicated HCC cases 
Table 6 Demographic, clinical and biochemical parameters among recurrent and eradicated HCC cases

\begin{tabular}{|c|c|c|c|c|}
\hline \multicolumn{2}{|c|}{ Parameter } & \multirow{2}{*}{$\begin{array}{l}\text { Recurrent HCC cases }(n=6) \\
62.8 \pm 3.1\end{array}$} & \multirow{2}{*}{$\begin{array}{l}\text { Eradicated HCC cases }(\boldsymbol{n}=\mathbf{3 0}) \\
56 \pm 6.9\end{array}$} & \multirow{2}{*}{$\frac{p}{<0.001}$} \\
\hline Age (ye & & & & \\
\hline $\mathrm{BMI}(\mathrm{Kg}$ & & $24.5 \pm 1.6$ & $24.7 \pm 2.3$ & 0.869 \\
\hline \multirow[t]{2}{*}{ Gender } & Male $n(\%)$ & $5(83.3)$ & $20(66.7)$ & \multirow[t]{2}{*}{$0.643^{\mathrm{a}}$} \\
\hline & Female $n(\%)$ & $1(16.7)$ & $10(33.3)$ & \\
\hline \multicolumn{2}{|c|}{ Child-Pugh score } & $7.2 \pm 0.8$ & $5.9 \pm 1.0$ & 0.008 \\
\hline \multicolumn{2}{|c|}{$\mathrm{ALT}(\mathrm{U} / \mathrm{L})$} & $67.8 \pm 38.9$ & $54.3 \pm 26.2$ & 0.295 \\
\hline \multicolumn{2}{|c|}{ AST $(U / L)$} & $62.8 \pm 41.4$ & $56.8 \pm 29.5$ & 0.672 \\
\hline \multicolumn{2}{|c|}{$\mathrm{ALP}(\mathrm{U} / \mathrm{L})$} & $80.0 \pm 24.5$ & $79.5 \pm 24.7$ & 0.964 \\
\hline \multicolumn{2}{|c|}{ S. albumin (g/dl) } & $3.3 \pm 0.2$ & $3.7 \pm 0.4$ & 0.036 \\
\hline \multicolumn{2}{|c|}{ T. bilirubin (mg/dl) } & $1.7 \pm 0.5$ & $1.5 \pm 0.4$ & 0.198 \\
\hline \multicolumn{2}{|c|}{ D. bilirubin (mg/dl) } & $0.8 \pm 0.2$ & $0.7 \pm 0.2$ & 0.119 \\
\hline \multicolumn{2}{|l|}{ INR } & $1.6 \pm 0.4$ & $1.3 \pm 0.4$ & 0.118 \\
\hline \multicolumn{2}{|c|}{ Hemoglobin (g/dL) } & $9.6 \pm 1.9$ & $10.2 \pm 1.4$ & 0.358 \\
\hline \multicolumn{2}{|c|}{ WBCs $\left(\times 10^{3} / \mathrm{mL}\right)$} & $4.2 \pm 2.4$ & $5.3 \pm 2.3$ & 0.301 \\
\hline \multicolumn{2}{|c|}{ Platelets $\left(\times 10^{3} / \mathrm{mL}\right)$} & $159.2 \pm 21.6$ & $146.2 \pm 37.4$ & 0.42 \\
\hline \multicolumn{2}{|c|}{ S. creatinine (mg/dL) } & $0.92 \pm 0.33$ & $0.84 \pm 0.34$ & 0.598 \\
\hline \multicolumn{2}{|c|}{ S. sodium (mEq/L) } & $137.3 \pm 4.1$ & $137.5 \pm 3.7$ & 0.907 \\
\hline \multicolumn{2}{|c|}{ S. potassium (mEq/L) } & $4.1 \pm 0.7$ & $4.0 \pm 0.5$ & 0.841 \\
\hline \multicolumn{2}{|c|}{ Number of HCC lesions } & $3.0 \pm 0.0$ & $1.7 \pm 0.7$ & $<0.001$ \\
\hline \multicolumn{2}{|c|}{ Size of HCC lesions (cm) } & $6.2 \pm 1.6$ & $3.3 \pm 1.2$ & $<0.001$ \\
\hline
\end{tabular}

${ }^{\text {a }}$ isher's exact test

That is why the difference in sCD163 level was insignificant between the 2 groups in our study.

Moreover, sCD163 shows an inferior sensitivity, specificity, and overall accuracy to that of AFP in discriminating HCC from LC groups. The AUC of sCD163 was lower than that of AFP (0.767 vs. 0.880$)$, indicating that AFP had a better diagnosing accuracy.

Interestingly, in the present study, sCD163 was significantly higher among patients with portal vein invasion $(p<0.001)$. That result agreed with those made by LingQun et al. [28] who stated that soluble CD163 was significantly higher among patients with microvascular invasion $(p=0.037)$. Most notably, sCD163 is a specific marker for the M2 macrophage which produces a variety of matrix metalloproteinase and chemokines such as MMP-2, CCL18, and CCL22 that facilitate cancer microvascular invasion [29].

Contradictory to our results, Konstantin et al. [30] stated that there was no association between sCD163 and vascular invasion.

On comparing the values of sCD163 and AFP before and after locoregional intervention, of notice, sCD163 showed a marked decline after intervention $(3.1 \pm 2.5$ post-intervention vs. $6.5 \pm 1.5$ pre-intervention; $p<$ 0.001 ), while AFP showed insignificant decline after intervention $(p=0.66)$. As observed in previous studies, sCD163 activity in HCC patients had a significant decrease after 1 month of intervention with TACE or RFA. Besides, its activity decreased close to the normal level, showing that serum CD163 activity appeared to be correlated with curative effect, thus might have an important value in post-treatment monitoring of HCC patients [30, 31].

Currently, there is a clinical need for monitoring the outcome of HCC prior to locoregional therapy to assess susceptibility and predict tumor response to locoregional therapies, and thus, an exploration of effective predictive indicators is of great significance and of great value in adopting timely treatment strategies to avoid recurrence and improve outcomes of HCC patients [32, 33]. To our knowledge, there is still limited number of studies that have investigated whether sCD163 could predict the prognosis of HCC patients treated with TACE or RFA. In the present work, sCD163 showed a good predictive value in comparing patients who were successfully eradicated and those who had failed locoregional treatment. At baseline, sCD163 had higher values in patients who had HCC recurrence after intervention as compared to eradicated cases $(8.4 \pm 0.4$ vs. $6.1 \pm 1.4 \mathrm{mg} / \mathrm{L} ; p<0.001)$. Also, during follow-up after intervention, there was a notable decline in sCD163 in eradicated cases from 6.1 \pm 1.4 to $2.3 \pm 1.4 \mathrm{mg} / \mathrm{L}(p<0.001)$, while those who had HCC recurrence showed a significant increase from 8.4 \pm 0.4 to $10.3 \pm 1.6 \mathrm{mg} / \mathrm{L}(p=0.022)$. 
The diagnostic accuracy of both AFP and sCD163 was assessed for discriminating between patients with recurrent $\mathrm{HCC}$ and those with eradicated HCC. AUC of AFP was low both before and after intervention 0.528 (95\% CI $0.311-0.744)$ and 0.642 (95\% CI 0.374-0.910), respectively $(p>0.05)$, while sCD163 showed a significantly higher AUC, 0.986 (95\% CI $0.000-1.000)$ and 0.994 (95\% CI $0.000-1.000)$, respectively $(p<0.001)$. At baseline, the best cutoff of sCD163 to predict HCC recurrence was $7.8 \mathrm{mg} / \mathrm{L}$, and post-intervention, it was 5 $\mathrm{mg} / \mathrm{L}$. Thus, this study highlights the importance of sCD163 as a prognostic predictor in ablative therapy for $\mathrm{HCC}$, which has an intrinsic problem of unavailability of histopathological prognostic features. These findings agreed with Konstantin et al. [30] who found that patients with high level of basal soluble CD163 with cutoff $\geq 8.0 \mathrm{mg} / \mathrm{L}$ had shorter progression-free survival. Also, these results were supported by Shabo and Svanvik [34] who reported that soluble CD163 is not only a parameter of macrophage activation but also an indicator of the M2 polarization of tumor-associated macrophage which support tumor progression. Consistently, recent studies introduced by Mark et al. [35] reported that increased plasma concentration of the soluble form of CD163 "a marker of alternatively activated M2" has been associated with poor survival in HCC patients indicating that M2 macrophage may be a potential target for HCC immunotherapy.

Some limitations should be considered in the present work. The number of studied populations was relatively small; CD163 levels were not assessed at different stages of HCC as regards tumor size and number; the followup period had to be extended to a more prolonged time.

\section{Conclusions}

It is concluded from this study that $\mathrm{sCD} 163$ has no reliable role as a diagnostic marker for $\mathrm{HCC}$, yet it has a good prognostic role in predicting the tumor response to locoregional therapies as it showed a significant decline in eradicated cases of HCC after treatment.

\footnotetext{
Abbreviations

AASLD: American Association for the Study of Liver Disease; AFP: Alphafetoprotein; BCLC: Barcelona Clinic Liver Cancer; CT: Computed tomography; EIA: Enzyme immunoassay; ELISA: Enzyme-linked immunosorbent assay; HCC: Hepatocellular carcinoma; HCV: Hepatitis C virus; LT: Liver transplantation; MRI: Magnetic resonance imaging; PVT: Portal vein thrombosis; ROC: Receiver operating characteristic; RFA: Radiofrequency ablation; sCD163: Soluble CD163; TACE: Transarterial chemoembolization; TAM: Tumor-associated macrophage
}

\section{Acknowledgements}

The authors express their gratitude to the members of the clinical Pathology Department, Faculty of Medicine, Ain Shams University, for their valuable participation.

\section{Authors' contributions}

MAS had made substantial contribution to the design in this study by collecting and revising the data. She had followed up the patients after treatment and shared in writing the manuscript. KAHM had made substantial contribution to the conception and analysis and revised the work and shared in writing the manuscript. AMH had contributed to the study by doing the interventional radiologic procedures and shared in revising and drafting the work. MHF had revised and tabulated the data and helped in statistical analysis of the collected data. ASA had shared in revising all the manuscript data and participated in its final revisions. ES is the

corresponding author. He collected the data, revised the statistical analysis of all data, and shared in writing the manuscript and its publication. All authors have read and approved the submitted version of manuscript. Each author agreed to be personally accountable for his own contributions and ensured that questions related to the accuracy or integrity of any part of the work are appropriately investigated and resolved.

\section{Funding}

The study was not funded.

\section{Availability of data and materials}

The datasets used and analyzed during the current study are available from the corresponding author on reasonable request.

\section{Declarations}

Ethics approval and consent to participate

The study was performed according to the ethical standards for human experimentation and in accordance with the ethical principles of the 1975 Declaration of Helsinki that was granted by the local Ethics Committee of Ain Shams University. Before enrollment in the study and after explaining the aim of the study and the nature of the investigations and interventions required, an informed written consent was obtained from all participants. Ethics committee's reference number 000017585.

\section{Consent for publication}

Not applicable.

\section{Competing interests}

The authors declare that they have no competing interests.

\section{Author details}

'Department of Internal Medicine, Faculty of Medicine, Ain Shams University, Cairo, Egypt. ${ }^{2}$ Department of Radiology, Faculty of Medicine, Ain Shams University, Cairo, Egypt.

Received: 16 January 2021 Accepted: 10 March 2021

Published online: 27 March 2021

\section{References}

1. Akinyemiju T, Abera S, Ahmed M, Alam N, Alemayohu MA et al (2017) The burden of primary liver cancer and underlying etiologies from 1990 to 2015 at the global, regional, and national level. JAMA Oncol 3(12):1683-1691. https://doi.org/10.1001/jamaoncol.2017.3055

2. Yang JD, Hainaut P, Gores GJ, Amadou A, Plymoth A, Roberts LR (2019) A global view of hepatocellular carcinoma: trends, risk, prevention and management. Nat Rev Gastroenterol Hepatol 16(10):589-604. https://doi. org/10.1038/s41575-019-0186-y

3. D'souza S, Lau Ck K, Coffin CS, Patel TR (2020) Molecular mechanisms of viral hepatitis induced hepatocellular carcinoma. World I Gastroenterol 26(38):5759-5783. https://doi.org/10.3748/wjg.v26.i38.5759

4. Zhang ZQ, Meng H, Wang N, Liang LN, Liu LN, Lu SM, Luan Y (2014) Serum microRNA 143 and microRNA 215 as potential biomarkers for the diagnosis of chronic hepatitis and hepatocellular carcinoma. Diagn Patho 9(1):135. https://doi.org/10.1186/1746-1596-9-135

5. Cho YK, Kim JK, Kim MY, Rhim H, Han JK (2009) Systematic review of randomized trials for hepatocellular carcinoma treated with percutaneous ablation therapies. Hepatology 49(2):453-459. https://doi. org/10.1002/hep. 22648

6. Xie ZB, Wang XB, Peng YC, Zhu SL, Ma L, Xiang BD, Gong WF, Chen J, You $X M$, Jiang JH, Li LQ, Zhong JH (2015) Systematic review comparing the 
safety and efficacy of conventional and drug-eluting bead transarterial chemoembolization for inoperable hepatocellular carcinoma. Hepatol Res 45(2):190-200. https://doi.org/10.1111/hepr.12450

7. Kanwal F, Kramer JR, Mapakshi S, Natarajan Y, Chayanupatkul M et al (2018) Risk of hepatocellular cancer in patients with non-alcoholic fatty liver disease. Gastroenterology 155(6):1828-1837. https://doi.org/10.1053/j.ga stro.2018.08.024

8. Hung YC, Lin CL, Liu CJ, Hung H, Lin SM, Lee SD, Chen PJ, Chuang SC, Yu MW (2015) Development of risk scoring system for stratifying population for hepatocellular carcinoma screening. Hepatology 61(6):1934-1944. https:// doi.org/10.1002/hep.27610

9. Hester CA, Rich NE, Singal AG, Yopp AC (2019) Comparative analysis of nonalcoholic steatohepatitis versus viral hepatitis and alcohol-related liver disease-related hepatocellular carcinoma. J Natl Compr Canc Netw 17(4): 322-329. https://doi.org/10.6004/jnccn.2018.7105

10. di Bisceglie AM, Sterling RK, Chung RT, Everhart JE, Dienstag JL, Bonkovsky HL, Wright EC, Everson GT, Lindsay KL, Lok ASF, Lee WM, Morgan TR, Ghany MG, Gretch DR, the HALT-C Trial Group (2005) Serum alpha-fetoprotein levels in patients with advanced hepatitis C: results from the HALT-C Trial. Hepatology 43(3):434-441. https://doi.org/10.1016/j.jhep.2005.03.019

11. Komohara Y, Fujiwara Y, Ohnishi K, Takeya M (2016) Tumor associated macrophages: potential therapeutic targets for anticancer therapy. Adv Drug Deliv Rev 99:180-185. https://doi.org/10.1016/j.addr.2015.11.009

12. Georgoudaki AM, Prokopec KE, Boura VF, Hellqvist E, Sohn S, Östling J, Dahan R, Harris RA, Rantalainen M, Klevebring D, Sund M, Brage SE, Fuxe J, Rolny C, Li F, Ravetch JV, Karlsson MCl (2016) Reprogramming tumorassociated macrophages by antibody targeting inhibits cancer progression and metastasis. Cell Reports 15(9):2000-2011. https://doi.org/10.1016/j. celrep.2016.04.084

13. Shirabe K, Mano Y, Muto J, Matono R, Motomura T, Toshima T, Takeishi K, Uchiyama H, Yoshizumi T, Taketomi A, Morita M, Tsujitani S, Sakaguchi Y, Maehara Y (2012) Role of tumor-associated macrophages in the progression of hepatocellular carcinoma. Surg Today 42(1):1-7. https://doi.org/10.1007/ s00595-011-0058-8

14. Gronbaek H, Sandahl TD, Mortensen C, Vilstrup H, Moller HJ et al (2012) Soluble CD163, a marker of Kupffer cell activation, is related to portal hypertension in patients with liver cirrhosis. Aliment Pharmacol Ther 36(2): 173-180. https://doi.org/10.1111/j.1365-2036.2012.05134.x

15. Bruix J, Sherman M (2011) Management of hepatocellular carcinoma: an update. Hepatology 53(3):1020-1022. https://doi.org/10.1002/hep.24199

16. Poulou LS, Botsa E, Thanou I, Ziakas PD, Thanos L (2015) Percutaneous microwave ablation vs radiofrequency ablation in the treatment of hepatocellular carcinoma. World J. Hepatol 7(8):1054-1063. https://doi.org/1 0.4254/wjh.v7.i8.1054

17. Facciorusso A (2018) Drug-eluting beads transarterial chemoembolization for hepatocellular carcinoma: current state of the art. World J Gastroenterol 24(2):161-169. https://doi.org/10.3748/wjg.v24.i2.161

18. Marengo A, Rosso C, Bugianesi E (2016) Liver cancer: connections with obesity, fatty liver, and cirrhosis. Annu Rev Med 67(1):103-117. https://doi. org/10.1146/annurev-med-090514-013832

19. Ioannou GN, Green PK, Beste LA, Mun EJ, Kerr KF, Berry K (2018) Development of models estimating the risk of hepatocellular carcinoma after antiviral treatment for hepatitis C. J Hepatol 69(5):1088-1098. https:// doi.org/10.1016/j.jhep.2018.07.024

20. Tzartzeva K, Obi J, Rich NE, Parikh ND, Marrero JA et al (2018) Surveillance imaging and alpha fetoprotein for early detection of hepatocellular carcinoma in patients with cirrhosis: a meta-analysis. Gastroenterology 154(6):1706-1718 e1

21. Stefaniuk P, Cianciara J, Wiercinska-Drapalo A (2010) Present and future possibilities for early diagnosis of hepatocellular carcinoma. World J Gastroenterology 16(4):418-424. https://doi.org/10.3748/wjg.v16.i4.418

22. Zhou SL, Zhou ZJ, Hu ZQ, Huang XW, Wang Z et al (2016) Tumor-associated neutrophils recruit macrophages and T-regulatory cells to promote progression of hepatocellular carcinoma and resistance to sorafenib. Gastroenterology 150(7):1646-1658 e17

23. Koji M, Kiyokaz H, Shinichi U et al (2018) Prognostic significance of CD68, CD163 and folate receptor-B positive macrophage in hepatocellular carcinoma. Exp and Ther Med 15:4465-4476

24. El-Zayadi AR, Badran HM, Barakat EM et al (2005) Hepatocellular carcinoma in Egypt: a single center study over a decade. World J Gastroenterology 11(33):5193-5198
25. Nishida N, Arizumi T, Hayaishi S, Takita M, Kitai S, Yada N, Hagiwara S, Inoue T, Minami Y, Ueshima K, Sakurai T, Ikai I, Kudo M (2012) Gender differences in the livers of patients with hepatocellular carcinoma and chronic hepatitis C infection. Digestive Diseases 30(6):547-553. https://doi.org/10.1159/ 000343057

26. Zhao S-X, Li W-C, Na F, Kong L-B, Zhang Q-S, Han F, Ren W-G, Cui P, JingHua D, Wang B-Y, Zhang Y-G, Wang R-Q, Kong L, Nan Y-M (2020) CD14 ${ }^{+}$ monocytes and $\mathrm{CD} 163^{+}$macrophages correlate with the severity of liver fibrosis in patients with chronic hepatitis C. Exp Ther Med 20(6):228. https:// doi.org/10.3892/etm.2020.9358

27. Hiraoka A, Horiike N, Akbar SM, Michitaka K, Matsuyama T et al (2005) Soluble CD163 in patients with liver diseases: very high levels of soluble CD163 in patients with fulminant hepatic failure. J Gastroenterol 40(1):5256. https://doi.org/10.1007/s00535-004-1493-8

28. Ling-Qun K, Xiao-Dong Z, Hua-Xiang $X$ et al (2013) The clinical significance of the CD163 and CD68 macrophages in patients with hepatocellular carcinoma. PLoS ONE 8(3):e59771

29. Fu-Biao K, Ling W, Dong L et al (2015) Hepatocellular carcinomas promote tumor-associated macrophage M2-polarization via increased B7-H3 expression. Oncology Reports 33(1):274-282

30. Konstantin K, Anthony R, Kira S et al (2015) Macrophage activation marker soluble CD163 may predict disease progression in hepatocellular carcinoma. Scand J Clin Lab Invest 76(1):64-73

31. Oliver W, Verena K, Dominik B et al (2013) Diagnostic and prognostic significance of cell death and macrophage activation markers in patients with hepatocellular carcinoma. J Hepatol 59:769-779

32. Schobert IT, Savic LJ, Chapiro J, Bousabarah K, Chen E, Laage-Gaupp F, Tefera J, Nezami N, Lin MD, Pollak J, Schlachter T (2020) Neutrophil-tolymphocyte and platelet-to-lymphocyte ratios as predictors of tumor response in hepatocellular carcinoma after DEB-TACE. Eur Radiol 30(10): 5663-5673. https://doi.org/10.1007/s00330-020-06931-5

33. Wang Q, Zhao P, He N, Sun JP, Li K, Zang CR, Zhao YN, Zhao Y, Zhang YH (2019) Combination of the gamma-glutamyltransferase-to-prealbumin ratio and other indicators may be a novel marker for predicting the prognosis of patients with hepatocellular carcinoma undergoing locoregional ablative therapies. Infect Agent Cancer 14(1):49. https:/doi.org/10.1186/s13027-019-0266-1

34. Shabo I, Svanvik J (2011) Expression of macrophage antigens by tumor cells. Adv Exp Med Biol 714:141-150. https://doi.org/10.1007/978-94-007-0782-5_7

35. Mark $Y$, Dongmei $X$, Lan $L$ et al (2017) Characterization of the immune microenvironment in hepatocellular carcinoma. Clin Cancer Res 23(23): 7333-7339

\section{Publisher's Note}

Springer Nature remains neutral with regard to jurisdictional claims in published maps and institutional affiliations.

\section{Submit your manuscript to a SpringerOpen ${ }^{\odot}$ journal and benefit from:}

- Convenient online submission

- Rigorous peer review

- Open access: articles freely available online

- High visibility within the field

- Retaining the copyright to your article

Submit your next manuscript at $>$ springeropen.com 